ISSN: 1907-9931 (print), 2476-9991 (online)

\title{
DISTRIBUSI Solen sp DI PERAIRAN KABUPATEN BANGKALAN
}

\author{
DISTRIBUTION OF SOlen sp IN BANGKALAN WATERS
}

\author{
Eva Ari Wahyuni ${ }^{1 *}$, Insafitri ${ }^{2}$, Gatot Ciptadi ${ }^{3}$, Mohammad Nur Ihsan ${ }^{3}$ \\ ${ }^{1}$ Staf Pengajar Program Studi Pendidikan IPA, FIP, Universitas Trunojoyo Madura \\ JI. Raya Telang PO.BOX 2 Kamal, Bangkalan, Madura, Jawa Timur \\ ${ }^{2}$ Staf Pengajar Program Studi IImu Kelautan, Fakultas Pertanian, Universitas Trunojoyo Madura \\ Jl. Raya Telang PO.BOX 2 Kamal, Bangkalan, Madura, Jawa Timur \\ ${ }^{3}$ Staf Pengajar Program Studi Produksi Ternak, Fakultas Peternakan, Universitas Brawijaya \\ Jl.Veteran, Malang, Madura, Jawa Timur \\ *Corresponding author e-mail: evaariw@yahoo.com, evaariw@trunojoyo.ac.id
}

Received: February 12, 2016/Accepted: March 29, 2016

\begin{abstract}
Solen sp potential needs to be developed on the island of Madura, particularly in Bangkalan. Solen sp utilization has increased which has the potential to overfishing. Therefore, this study aims to determine the density of Solen $s p$ and their ecology in the waters Modung village, Modung District, Bangkalan. The experiment was conducted in April 2015 using the descriptive method. The materials used include Solen $s p$ and physico-chemical parameters of the environment (temperature, salinity, $\mathrm{pH}$, and substrate). The analyzes were conducted at the Laboratory of Marine Science, Department of Marine Sciences, Trunojoyo University of Madura by using the tool grabsampler, sieveshaker, and pipetting with gravimetric method. The analysis shows the range of values of temperature between $29-30^{\circ} \mathrm{C}$, salinity between $31-32 \mathrm{ppt}$, $\mathrm{pH}$ were 7.9-8.0 and the type of substrate in the form of sandy mud, as well as the density of Solen sp from 8-10 individuals $/ \mathrm{m}^{2}$. All measurement results indicate normal conditions and in accordance with the sea water quality standard for marine life, which can be a suitable habitat for the growth and development of Solen sp. This condition is thought to affect the density of Solen sp.
\end{abstract}

Keywords: Bangkalan, density, distribution, Solen sp, substrate.

\section{ABSTRAK}

Potensi Solen sp perlu dikembangkan di pulau Madura, khususnya di Kabupaten Bangkalan. Pemanfaatan Solen sp mengalami peningkatan sehingga berpotensi overfishing. Untuk itu, penelitian ini bertujuan untuk mengetahui kepadatan Solen sp dan ekologinya di perairan desa Modung, Kecamatan Modung, Kabupaten Bangkalan. Penelitian dilaksanakan pada bulan April 2015 dengan metode deskriptif. Materi dan bahan yang digunakan diantaranya Solen sp dan parameter fisika-kimia lingkungan (suhu, salinitas, $\mathrm{pH}$, dan substrat). Analisa dilakukan di Laboratorium IImu Kelautan, Program studi/Jurusan IImu Kelautan Universitas Trunojoyo Madura dengan menggunakan alat grabsampler, sieveshaker, dan pemipetan dengan metode gravimetri. Hasil analisa menunjukkan kisaran nilai suhu $29-30^{\circ} \mathrm{C}$, salinitas 31-32 ppt, pH 7.9-8.0, dan jenis substrat berupa lumpur berpasir, serta kepadatan Solen sp 8-10 individu/m2. Semua hasil pengukuran menunjukkan kondisi normal dan sesuai dengan baku mutu air laut untuk biota laut, sehingga dapat menjadi habitat yang cocok untuk tumbuh dan kembang Solen sp. Kondisi ini diduga mempengaruhi kepadatan Solen sp.

Kata kunci: Bangkalan, distribusi, kepadatan, Solen sp, substrat. 


\section{PENDAHULUAN}

Kabupaten Bangkalan merupakan salah satu kabupaten di Pulau Madura yang memiliki potensi sebagai penghasil komoditas Solen sp. Ukuran panjang Solen sp di perairan Kabupaten Bangkalan $(1.9-6.5 \mathrm{~cm})$ lebih kecil dibandingkan Solen $\mathrm{sp}$ di perairan Kabupaten Sampang (Wahyuni et al., 2015a), tetapi kelimpahan Solen sp di perairan Kabupaten Bangkalan diduga relative sama dengan kelimpahan Solen sp di Kabupaten Sampang sebesar 7-9 individu untuk area transek $25 \times 25 \mathrm{~cm}^{2}$ dan kabupaten lainnya di Pulau Madura. Tingginya nilai gizi yang terkandung pada Solen sp (Rusyadi, 2006) menjadikan spesies ini berpotensi overfishing (Abida et al., 2013) sehingga perlu dipertimbangkan untuk mencari solusinya, diantaranya dengan usaha budidaya.

Secara umum, ukuran Solen sp berkisar $5-7.5 \mathrm{~cm}$ bilamana dengan pertumbuhan maksimal (Izzati, 2010). Bentuk atau morfologinya antara lain memiliki katub yang membuka satu sama lain dengan bentuk memanjang, berbentuk tipis, permukaan halus, dan sedikit mengkilap dengan kerutan konsentris sangat redup (Counago and Gomez, 2011). Hampir sebagian besar kelas bivalva, termasuk Solen sp, memiliki habitat hidup berupa substrat pasir berlumpur dan kecepatan arus yang lemah (Izzati, 2010). Dengan mempertimbangkan potensi gizi dan nilai ekonominya yang tinggi sehingga berpeluang terjadi overfishing, maka perlu untuk dilakukan kajian atas kepadatan Solen sp di Kabupaten Bangkalan agar dapat diketahui potensi lestarinya.

\section{MATERI DAN METODE}

Penelitian dilaksanakan pada bulan April 2015 di perairan Desa Modung, Kecamatan Modung, Kabupaten Bangkalan. Materi utama berupa Solen sp, substrat sedimen, dan parameter fisikakimia perairan. Metode yang digunakan dalam penelitian ini adalah metode deskriptif untuk menggambarkan kondisi atau fenomena, baik alamiah maupun non-alamiah (Sukmadinata, 2006). Solen sp diambil secara acak dengan harapan setiap anggota populasi mempunyai peluang yang sama untuk dipilih (Umar, 1999) dengan menggunakan alat rajeg dan dilakukan pada kondisi surut terendah dengan transek ukuran $25 \times 25 \mathrm{~cm}$. Pengukuran data parameter lingkungan meliputi suhu, salinitas, $\mathrm{pH}$, dan substrat. Substrat diambil menggunakan grabsampler, sedimen yang terambil dimasukkan dalam kantong plastik untuk analisa ukuran butir. Sedimen dikeringkan, dipisahkan antara yang mudah terurai dengan yang menggumpal, dan dianalisa dengan sieveshaker (untuk sedimen yang mudah terurai) dan gravimetri (sedimen tersuspensi, BSN 2004). Hasil analisa dengan sieve shaker dan gravimetri diplot pada grafik dengan metode Buchanan (1984) dalam Holme and McIntyre (1984) dan dianalisa ukuran butir (Siswanto, 2010a,b). Hasil pengukuran kemudian dianalisa secara deskriptif. Untuk analisa kepadatan Solen sp menggunakan persamaan dari Odum (1971) dalam Rusyadi (2006) yang menyatakan bahwa kerapatan populasi adalah besarnya populasi dalam hubungannya dengan satuan ruangan yang umumnya dinyatakan sebagai hasil jumlah individu atau biomass populasi per satuan luas atau volume.

Kerapatan Individu $=\frac{\text { Jumlah kerang pisau (Solen } s p)}{\text { Luas }\left(\mathrm{cm}^{2}\right)}$ 


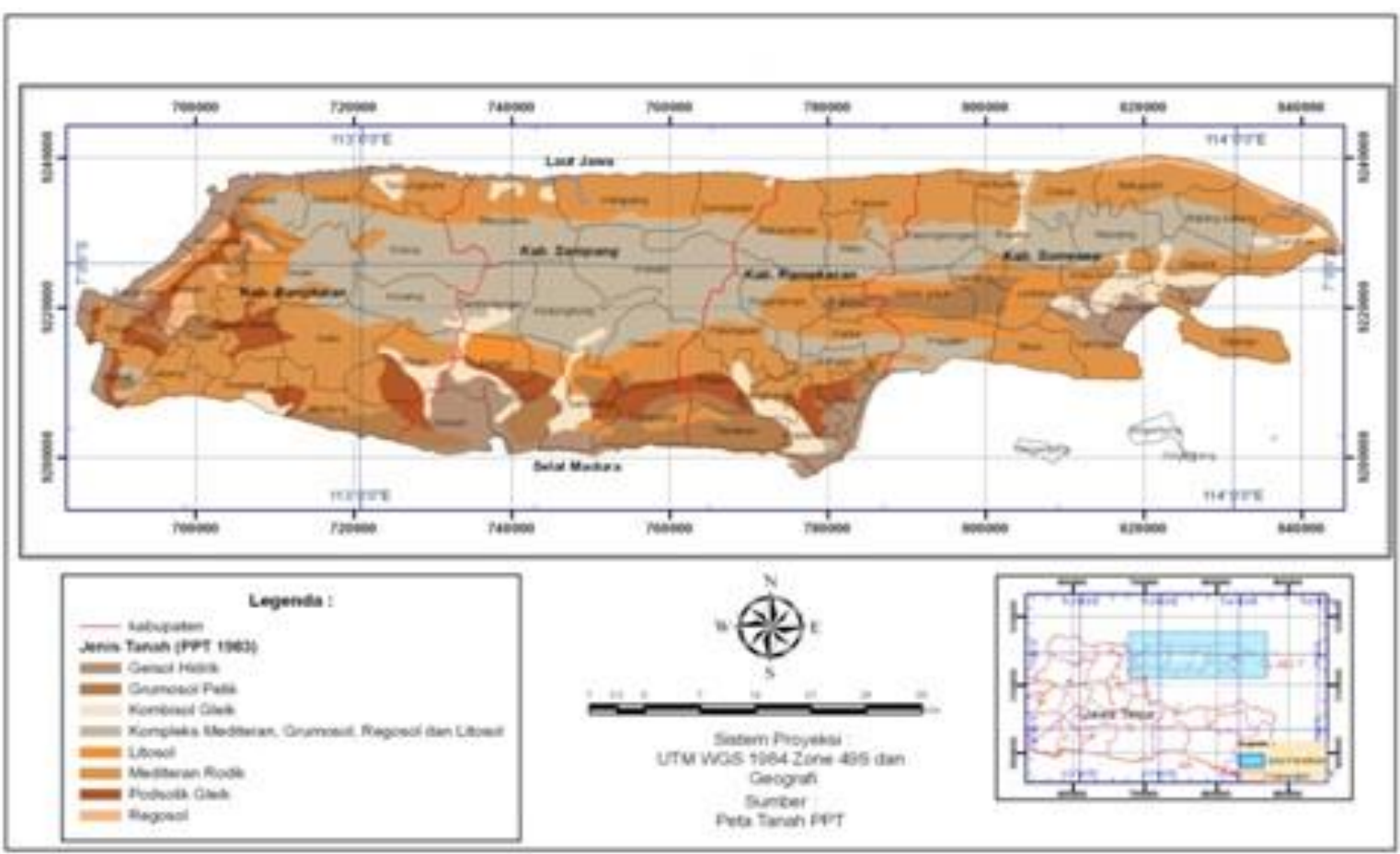

Gambar 1. Lokasi penelitian

\section{HASIL DAN PEMBAHASAN}

Perairan di Desa Modung, Kecamatan Modung, Kabupaten Bangkalan merupakan bagian dari perairan Selat Madura dengan topografi landai dan jenis substrat lumpur berpasir (Tabel 1, Gambar 1, 2). Umumnya daerah perairan di Kabupaten Bangkalan didominasi oleh substrat lumpur, lumpur berpasir, pasir, dan sebagian berbatu (Siswanto, 2010b). Lokasi penelitian relatif dekat dengan jembatan Suramadu yang merupakan perairan relatif keruh dengan dinamika arus dan gelombang yang relatif kecil; tetapi memberikan pengaruh terhadap distribusi sebaran sedimen tersuspensi sebagai akibat dominasi subtrat sedimen yang berlumpur (Siswanto, 2010a).

Kondisi perairan di lokasi penelitian relatif wajar dengan kisaran suhu rata-rata sebesar $29-30^{\circ} \mathrm{C}$ (Tabel 1). Kisaran nilai suhu ini sesuai dengan nilai baku mutu air laut yang berkisar $28-32^{\circ} \mathrm{C}$ (KepmenLH, 2004). Profil sebaran suhu permukaan diperairan Selat Madura relatif normal dan homogen dengan fluktuasi relatif kecil (Prasetyo dan Siswanto, 2013) sehingga memudahkan biota untuk beradaptasi dan berkembang biak.

Tabel 1. Pengukuran parameter lingkungan dan kepadatan Solen sp rata-rata

\begin{tabular}{cccccc}
\hline Minggu & Suhu $\left({ }^{\circ} \mathbf{C}\right)$ & $\begin{array}{c}\text { Salinitas } \\
(\mathbf{p p t})\end{array}$ & $\mathbf{p H}$ & Substrat & $\left.\begin{array}{c}\text { Kelimpahan Solen sp } \\
\text { rata-rata (individu/(cm }\end{array}\right)$ \\
\hline 1 & 29 & 31 & 7.9 & & 8 \\
2 & 29 & 31 & 8.0 & Lumpur & 10 \\
3 & 30 & 32 & 8.0 & berpasir & 9 \\
4 & 29 & 31 & 8.0 & & 10 \\
\hline
\end{tabular}


Profil salinitas selama periode pengambilan data lapang menunjukkan kisaran 31-32 ppt (Tabel 1). Profil tersebut menunjukkan kondisi salinitas rata-rata diperairan laut di daerah tropis (Prasetyo dan Siswanto, 2013). Jika dibandingkan dengan kisaran nilai salinitas untuk baku mutu air laut untuk biota air yang berkisar 29-34 ppt (KepmenLH, 2004), maka kondisi lingkungan di lokasi penelitian berada pada level normal. Prasetyo dan Siswanto (2013) menyimpulkan bahwa fluktuasi salinitas diperairan laut tropis, khususnya di perairan Selat Madura, relatif kecil $( \pm 5 \mathrm{ppt}$ terhadap perubahan rata-rata salinitas musiman). Kondisi pH di lokasi penelitian berkisar 7.9-8.0 menunjukkan $\mathrm{pH}$ normal untuk perairan laut. Hal ini bersesuaian kisaran nilai $\mathrm{pH}$ dalam KepmenLH No 51 tahun 2004 yang berkisar 7.0-8.5.

Hasil analisa contoh sedimen menunjukkan jenis substrat lumpur berpasir (Tabel 1, Gambar 2) yang mengindikasikan bahwa substrat lebih didominasi oleh lumpur dengan sedikit campuran pasir (Budihardjo dan Siswanto, 2013; Radhista et al., 2013). Karakteristik substrat tersebut akan mudah teraduk oleh energi gelombang (Siswanto, 2010a,b; Siswanto dan Syah, 2013b) maupun arus (Shofiyanti dan Siswanto, 2013; Siswanto dan Syah, 2013a) meskipun dalam kategori lemah atau kecil (Siswanto, 2010a,b; Mukhtasor, 2007).

Kelimpahan Solen sp rata-rata (Tabel 1) menunjukkan kisaran 8-10 individu pada area transek $25 \times 25 \mathrm{~cm}^{2}$. Jumlah tersebut menunjukkan jika spesies Solen sp dilokasi penelitian relative padat dan setara dengan kepadatan Solen sp di perairan Kabupaten Sampang yang berkisar 7-9 individu untuk area transek $25 \times 25 \mathrm{~cm}^{2}$ pada periode pengambilan data pada bulan April 2015 dengan beberapa indikator perairan berupa suhu $\left(28-30^{\circ} \mathrm{C}\right)$, salinitas $(32-34 \mathrm{ppt})$, dan $\mathrm{pH}$ (7.98.2) (Wahyuni et al., 2015a). Jenis substrat maupun parameter fisika-kimia yang merupakan salah satu indicator untuk memahami ekologi Solen sp di lokasi penelitian identik dengan ekologi di perairan Kabupaten Sampang (Wahyuni et al., 2015b). Informasi awal tentang kepadatan Solen sp menjadi salah satu dasar untuk memahami dan mempelajari potensi lestari Solen $\mathrm{sp}$ sebagai salah satu upaya dalam mencari solusi untuk mengendalikan pengaruh dan potensi overfishing.

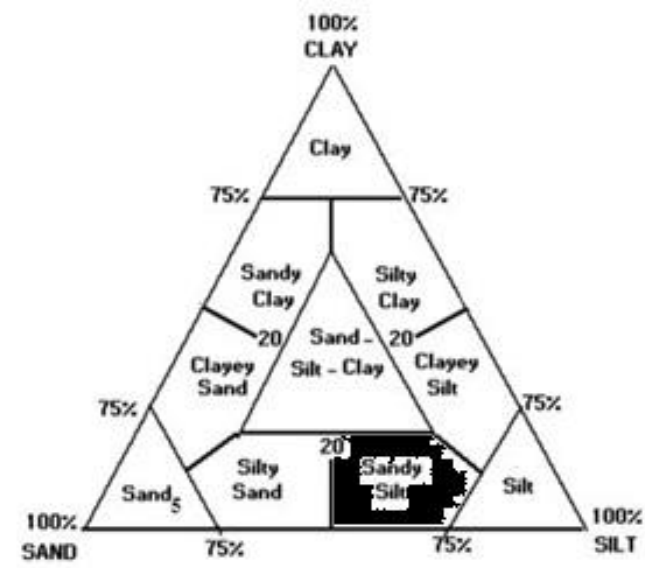

Gambar 2. Jenis substrat sedimen di lokasi penelitian

\section{KESIMPULAN DAN SARAN}

Kisaran nilai suhu $29-30^{\circ} \mathrm{C}$, salinitas $31-32 \mathrm{ppt}$, pH 7.9-8.0, dan jenis substrat berupa lumpur berpasir, serta kepadatan Solen $\mathrm{sp}$ 8-10 individu/ $\mathrm{m}^{2}$. Semua hasil pengukuran menunjukkan kondisi normal dan sesuai dengan baku mutu air laut untuk biota laut, sehingga dapat menjadi 
habitat yang cocok untuk tumbuh dan kembang Solen sp. Kondisi ini diduga mempengaruhi kepadatan Solen sp.

\section{UCAPAN TERIMA KASIH}

Ucapan terimakasih disampaikan kepada DP2M DIKTI atas pendanaan untuk kegiatan penelitian melalui skim hibah PEKERTI, Saudara Aditya Januar dan Saudara Mohammad Imron Efendy (mahasiswa Program Studi IImu Kelautan Universitas Trunojoyo), dan staf laboran di Laboratorium IImu Kelautan, Program Studi IImu Kelautan Universitas Trunojoyo; serta Saudara Ashari Wicaksono (mahasiswa pascasarjana Ilmu Kelautan Universitas Diponegoro) atas bantuan yang diberikan selama penelitian.

\section{DAFTAR PUSTAKA}

Abida, I. W, Wahyuni, E. A., \& Efendy, M. (2014). Hubungan panjang berat lorjuk (Solen spp) di perairan pesisir pantai selatan Pulau Madura. Jurnal Kelautan, 7(1), 24-29.

Budiharjo, M. Y., \& Siswanto, A. D. (2013). Distribusi ukuran sedimen di perairan Selat Madura, Kabupaten Bangkalan. Prosiding Seminar Nasional Hasil Perikanan dan Kelautan. Fakultas Perikanan dan Ilmu Kelautan. Universitas Diponegoro. Semarang.

[BSN] Badan Standarisasi Nasional (2004). Air dan limbah-bagian 3 : cara uji tersuspensi total (total suspended solid) secara gravimetri. SNI 06-6989.3-2004, 1-10.

Counago, S. D., \& Gomez, C. L. (2011). Chapter 2: anatomy razor clams: biology, aquaculture, and fisheries. Xunta de Galicia, Conselleria do Mar, 40-64 p

Holme, N. A., \& Mclntyre, A. D. (1984). Methods for the study of marine benthos. Second edition. Blackwell Scientific Publication. Oxford. $387 \mathrm{hlm}$.

Izzati, L. (2010). Aktivitas anti oksidan dan komponen bioaktif kerang pisau (Solen spp). Departemen Teknologi Hasil Perikanan. Fakultas Perikanan dan IImu Kelautan. IPB. Bogor.

Mukhtasor (2007). Pencemaran pesisir dan laut. Jakarta : PT Pradnya paramita.

Prasetyo, E., \& Siswanto, A. D. (2013). Variabilitas suhu dan salinitas di perairan Selat Madura, Kabupaten Bangkalan. Prosiding Seminar Nasional Hasil Perikanan dan Kelautan. Fakultas Perikanan dan IImu Kelautan. Universitas Diponegoro. Semarang.

Radhista, V. R., Siswanto, A. D., \& Wahyuni, E. A. (2013). Studi sebaran sedimen secara vertikal di perairan Selat Madura Kabupaten Bangkalan. Jurnal Rekayasa. Oktober.

Rusyadi, S. (2006). Karakteristik gizi dan potensi pengembangan kerang pisau (Solen spp) di perairan Kabupaten Pamekasan Madura. Skripsi. Program Studi Teknologi Hasil Perikanan. FPIK. IPB.

Siswanto A. D. (2010a). Analisa stabilitas garis pantai di Kabupaten Bangkalan. Tesis. Surabaya : Institut Teknologi Sepuluh Nopember.

Siswanto A. D. (2010b). Analisa sebaran total suspended solid (TSS) di perairan pantai Kabupaten Bangkalan pasca jembatan suramadu. Jurnal Kelautan, 2(2), 16-20.

Shofiyanti, E. R., \& Siswanto, A. D. (2013). Arus permukaan dan konsentrasi total suspended solid (TSS) di perairan Selat Madura, Kabupaten Bangkalan. Prosiding Seminar Nasional Hasil Perikanan dan Kelautan. Fakultas Perikanan dan IImu Kelautan. Universitas Diponegoro. Semarang.

Siswanto, A. D., \& Syah, A. F. (2013a). Karakteristik arus di di perairan Selat Madura, Kabupaten Bangkalan. Prosiding Seminar Nasional Hasil Perikanan dan Kelautan. Fakultas Perikanan dan IImu Kelautan. Universitas Diponegoro. Semarang.

Siswanto, A. D., \& Syah, A. F. (2013b). Karakteristik gelombang di perairan Selat Madura, Kabupaten Bangkalan. Prosiding Pertemuan IImiah Tahunan (PIT) Ikatan Sarjana Oseanologi Indonesia. BPPT-Jakarta.

Sukmadinata (2006). Metode penelitian pendidikan. Rosdakarya. Bandung.

Umar, H. (1999). Metode penelitian. PT Gramedia Pustaka Tama. Jakarta. 
Wahyuni, E. A., Insafitri, Ciptadi, G., \& Ihsan, M. N. (2015a). Ekologi kerang pisau (Solen sp) di perairan Kabupaten Sampang. Prosiding Seminar Nasional Kelautan dan Perikanan V. FPIK. Universitas Brawijaya. Malang.

Wahyuni, E. A., Insafitri, Ciptadi, G., \& Ihsan, M. N. (2015b). Sebaran kerang pisau (Solen sp) di perairan Kabupaten Sampang. Prosiding Simposium Nasional Kelautan dan Perikanan II. FIKP. Universitas Hasanuddin. Makasar. 